\title{
Mineral Reconstruction Model for Spectroscopy Logging Data
}

\author{
Fangfang $\mathrm{Wu}$ \\ School of Energy Resources \\ China University of Geosciences (Beijing) \\ Beijing, China \\ Wufang66@163.com \\ Jinlong $\mathrm{Wu}$ \\ Petro Technical Service \\ Schlumberger \\ Beijing, China \\ JWu7@slb.com
}

\author{
Liuzhong Li \\ Tuha Oilfield \\ Hami, China \\ 66138892 @qq.com \\ Lei Yang \\ Petro Technical Service \\ Schlumberger \\ Beijing, China \\ LYang6@slb.com
}

Research Institute of exploration and development

\begin{abstract}
With the deepening of the unconventional reservoir exploration, formation lithology evaluation is becoming more and more difficult, because in addition to the common minerals such as quartz, calcite, illite, some special minerals like pyrite, gypsum, dolomite, ankerite can also been seen. However, conventional well logging curves are difficult to identify these complex minerals. Spectroscopy tool, such as Element Capture Spectroscopy tool (ECS) can measure the capture spectrums of the main elements in formation such as silicon, calcium, iron, sulfur, and then the absolute contents of different minerals can be derived. This provides a new train of thought for unconventional reservoir lithology evaluation. But if feldspar, chlorite, dolomite, pyrite minerals are rich in the formation, default outputs from ECS will differ from core analysis results greatly. Based on a certain amount of core samples, this study analyzed the absolute contents of elements and minerals, and established the suitable complex mineral reconstruction model for the target formation in $\mathrm{K}$ block, and laid a solid foundation for tight sand mineral evaluation and reservoir evaluation.
\end{abstract}

Keywords- Element Capture Spectroscopy; Mineral reconstruction model; Core analysis; Dual Range Fourier Transform Infrared Spectroscopy; Complex Lithology

\section{INTRODUCTION}

Badaowan and Sangonghe formation of $\mathrm{K}$ block in Tuha oilfield is a tight sandstone reservoir, the reservoir lithology minerals are very complex, besides the common brittle minerals like quartz, the formation contains a lot of mica, sodium, feldspar and a small amount of magnesium carbonate minerals. Clay minerals include illite and a certain amount of chlorite and kaolinite. Complex mineral composition, especially the presence of minerals such as mica, chlorite lowers the applicability of standard element to mineral transformation model $[1,2]$. Establishing a new mineral reconstruction model suitable for the region will help a lot for better understanding of the complex minerals in this tight gas reservoir.
Thirty four core samples from two wells in K Field were analyzed for chemical and mineralogical content. Quantitative mineralogy was measured using SDR's Dual Range Fourier Transform Infrared (DR-FTIR) technique. Chemical analysis was performed by SGS Laboratories in Canada using X-ray fluorescence for major oxides analysis, LECO for sulfur, and ICP-AES and ICP-MS for the multielement package. The chemistry data were used as a quality check on the mineralogy. The chemistry and mineralogy data were combined to derive optimized schemes for evaluation of formation lithology.

\section{CHEMICAL ANALYSIS}

The samples are crushed, homogenized, and split into two portions using a micro-splitter. One portion is analyzed for mineralogy and the other for chemical content.

The analytical techniques for these samples include $\mathrm{x}$ ray fluorescence (XRF) for major oxides, LECO for sulfur, organic carbon, and CO2, and ICP-AES and ICP-MS for multi-element analysis. $\mathrm{FeO}$ is measured by titration. The analysis includes these elements and compounds:

$\mathrm{SiO} 2, \mathrm{Al} 2 \mathrm{O} 3, \mathrm{Fe} 2 \mathrm{O} 3, \mathrm{FeO}, \mathrm{MgO}, \mathrm{CaO}, \mathrm{Na} 2 \mathrm{O}, \mathrm{K} 2 \mathrm{O}$, $\mathrm{TiO} 2, \mathrm{P} 2 \mathrm{O} 5, \mathrm{MnO}, \mathrm{Cr} 2 \mathrm{O} 3$, Loss on Ignition (LOI, total volatiles), $\mathrm{S}$, organic $\mathrm{C}, \mathrm{CO} 2, \mathrm{Ag}, \mathrm{Al}, \mathrm{As}, \mathrm{B}, \mathrm{Ba}, \mathrm{Be}, \mathrm{Bi}$, $\mathrm{Ca}, \mathrm{Cd}, \mathrm{Ce}, \mathrm{Co}, \mathrm{Cr}, \mathrm{Cs}, \mathrm{Cu}, \mathrm{Dy}, \mathrm{Er}, \mathrm{Eu}, \mathrm{Fe}, \mathrm{Ga}, \mathrm{Gd}, \mathrm{Ge}, \mathrm{Hf}$, Ho, In, K, La, Li, Lu, Mg, Mn, Mo, Nb, Nd, Ni, P, Pb, Pr, $\mathrm{Rb}, \mathrm{Sb}, \mathrm{Sc}, \mathrm{Sm}, \mathrm{Sn}, \mathrm{Sr}, \mathrm{Ta}, \mathrm{Tb}, \mathrm{Th}, \mathrm{Ti}, \mathrm{Tl}, \mathrm{Tm}, \mathrm{U}, \mathrm{V}, \mathrm{W}, \mathrm{Y}$, $\mathrm{Yb}, \mathrm{Zn}, \mathrm{Zr}$

The major elements measured by XRF are reported as oxides (i.e., $\mathrm{Si}$ as $\mathrm{SiO} 2, \mathrm{Fe}$ as $\mathrm{Fe} 2 \mathrm{O} 3, \mathrm{Al}$ as $\mathrm{Al} 2 \mathrm{O} 3$, etc.). Some of these elements are repeated in the multi-element package, but the XRF data are more accurate for the major elements. As can be expected, the major elements reflect the mineralogical or lithological variations in the formations.

\section{MINERAL ANALYSIS}

The more commonly used $\mathrm{x}$-ray diffraction technique is excellent for the identification of minerals and 
qualitative analysis but suffers from many inherent limitations in quantitative analysis $[3,4]$. The Dual Range Fourier Transform Infrared Spectroscopy (DR-FTIR) technique is better for quantification [5-8].

Minerals have characteristic properties that can be effectively used in quantitative analysis. Among these properties are chemical bond vibrational energies that lead to characteristic infrared (IR) absorbance spectra. Mineralogy can be quantitatively solved from the sample spectrum and the mineral constituents' spectra. Of course, many variations exist that can affect the mineral properties including their infrared spectra. To account for natural variability in minerals, the DR-FTIR procedure uses 63 different mineral standards representing 28 minerals. We include multiple standards for quartz, calcite, dolomite, kaolinite, illite, smectite and chlorite. The use of multiple mineral standards is an important reason why the procedure has attained such a high degree of accuracy. In the case of feldspars, we have solved for the Na-, K-, and Ca-feldspar end member spectra and solved for the fractions of the end members in the samples [9]. The use of Fourier Transform produces smooth spectra with reduced noise content that are suitable for full spectrum analysis. The SDR procedure also combines the mid-IR spectrum with the far-IR spectrum prior to data processing. The resulting dual range FTIR mineralogy is more accurate than possible from either mid-IR or far-IR alone. Detection limits are generally approximately 1-2 wt $\%$.

\section{Mineralogy AND CHEMiCAl ANALYSIS RESUlts}

Key mineral abundances are displayed as a function of sample number in Fig .1.

Two main rock types were observed on the basis of the mineralogy and chemistry; these correspond to samples from the Sangonghe Formation and from the Badaowan Formation. Sangonghe Formation samples display a mineralogy dominated by quartz and muscovite, with lesser illite and some magnesium and iron carbonate minerals present. Badaowan Formation samples display lesser quartz and muscovite, significant amounts of sodium plagioclase, and a more complex clay mineralogy including illite, chlorite, and kaolinite, with a general absence of carbonates. This complex mineralogy, particularly the high concentrations of mica, complicates the application of the standard elemental composition to mineralogy transform in this environment. Local mineralogy models have been developed for each of the formations based on the results of the core chemistry and mineralogy results.

The samples analyzed display a complex mineral assemblage characteristic of a relatively immature sediment derived from an igneous source. In addition to quartz, which exists in concentrations up to approximately $69 \%$, major framework minerals include Na-plagioclase, which occurs in concentrations up to approximately $18 \%$ and muscovite, which occurs in concentrations up to approximately $37 \%$. Minor framework minerals include Kfeldspar and more mafic minerals such as apatites, pyroxenes, and olivines. Minor amounts of carbonate minerals are present, dominated by dolomite, which occurs in concentrations up to approximately $13 \%$, and ankerite, which occurs in concentrations up to approximately $10 \%$. Lesser amounts of calcite and siderite were also observed.
Clay mineralogy is dominated by illite, occurring in concentrations up to approximately $36 \%$. Kaolinite and chlorite are also relatively common, occurring in concentrations up to approximately $13 \%$.

As would be expected in a silicate-dominated mineralogy, the chemistry is dominated by the oxide of silicon. Aluminum, sodium, and potassium oxides occur in lesser amounts, primarily associated with feldspars, clay minerals and mica, while calcium oxide is associated primarily with carbonate minerals. Iron and magnesium oxides are associated with mafic minerals and carbonates. These oxides, along with loss on ignition (primarily $\mathrm{H}_{2} \mathrm{O}+$ associated with clay minerals and $\mathrm{CO}_{2}$ associated with carbonates), account for over 98 wt \% of the chemical composition of the samples analyzed.

Major element chemical analysis results are shown as a function of sample number in Fig.2. Aluminum and potassium correlate with both variations in clay mineral and muscovite content. The high proportion of muscovite, and its similar chemical composition and physical properties to illite, significantly complicate the evaluation of clay content. Sodium correlates almost exclusively with sodium plagioclase, as would be expected in this mineral assemblage. Calcium and magnesium correlate with the small amounts of carbonate minerals observed in these samples. Iron displays a complicated behavior. Iron would be expected to correlate with clay content, a relationship taken advantage of in computation of mineralogy. However, the general relationship between iron and clay content is complicated by the presence of varying amounts of chlorite, as well as the more commonly occurring illite. Iron-bearing carbonate minerals are also present in an immature mineralogical assemblage of igneous origin. And it is also likely that various iron-bearing oxides may also be present that are not detected by DR-FTIR; this may explain the somewhat erratic behavior in the iron concentration in the first ten samples that is not reflected in the measured mineralogy. The similar behavior observed for titanium provides additional evidence for the presence of such heavy minerals.

The chemical concentration data are used to independently monitor the quality of the DR-FTIR mineralogy. For validation of the core analysis, each mineral identified by the DR-FTIR analysis is assigned a fixed chemical composition that is taken either from the chemical formula or from mineral standard analyses [10]. The mineral composition of each sample is then multiplied by the concentration found by DR-FTIR to produce an estimated elemental composition of each sample for each element. 


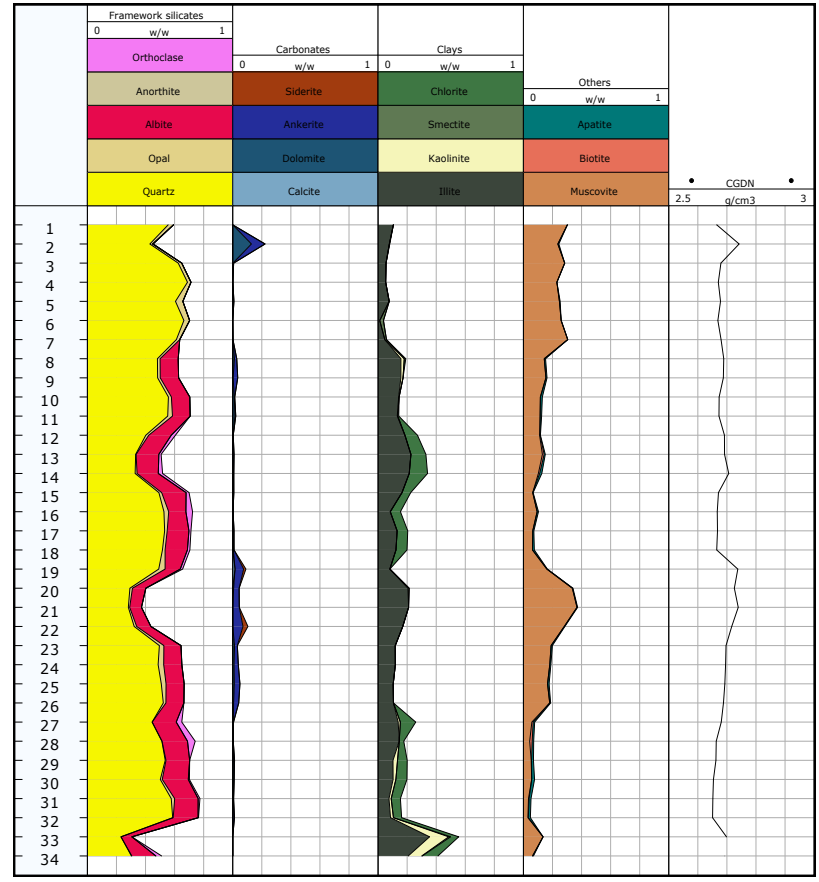

Figure 1. Mineralogy measured by DR-FTIR.

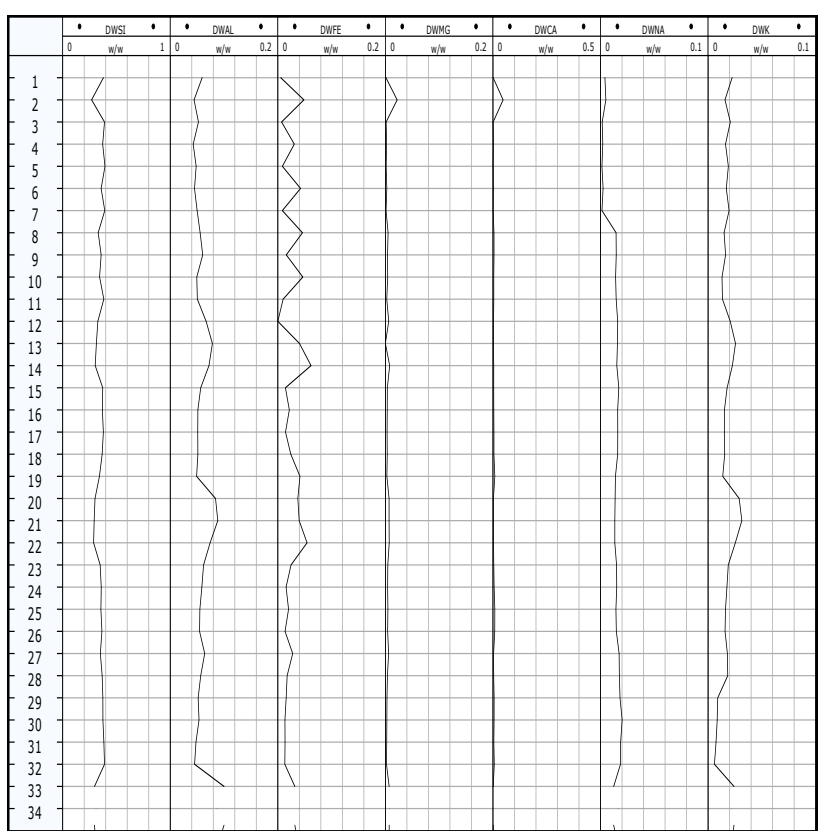

Figure 2. Elemental concentrations

The results of the validation for major elements are displayed graphically in Fig .3. In this figure, the elemental concentrations reconstructed from the mineralogy are plotted against the concentrations measured on each sample, and a 1:1 line is shown for comparison.

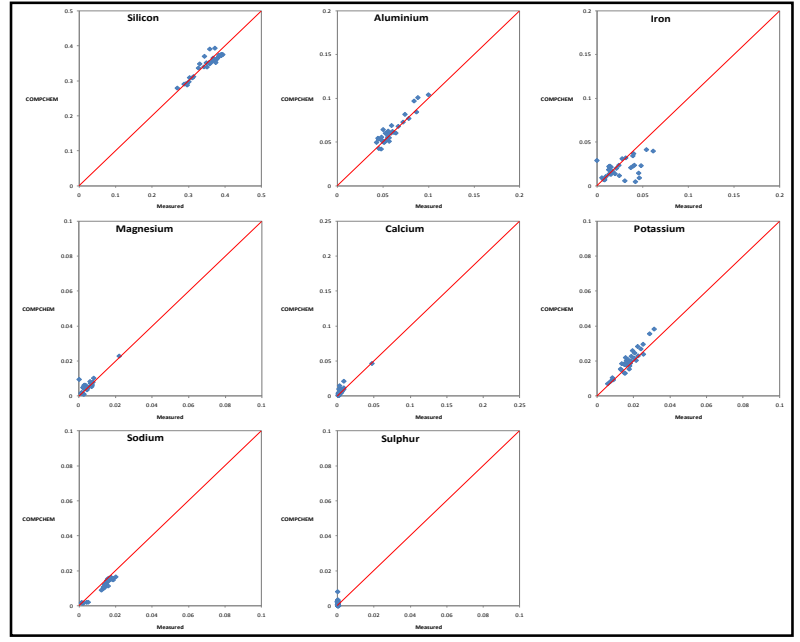

Figure 3. Measured elemental concentrations plotted against concentrations reconstructed from the DR-FTIR mineralogy.

The comparison between measured elemental concentrations and those reconstructed from mineralogy is very good overall. Reconstruction of iron appears to be relatively poorer than for other elements, particularly for the uppermost ten samples; however this is likely due to the presence of iron in carbonates, pyroxenes, and amphiboles, where it occurs as part of a solid solution series with other cations, whereas the validation procedure uses end-point mineral compositions. The presence of small amounts of iron-bearing oxides, which would be expected in this type of environment, would also account for the apparently poor reconstruction of iron.

\section{Mineral RECONSTRUCTION}

One of the major applications of ECS is to compute formation mineralogy, or more specifically the mineral groups: CLAY (illite, kaolinite, smectite, chlorite, glauconite); CARBONATE (calcite, dolomite); a sulfur mineral (pyrite or anhydrite); and QFM (quartz, feldspar, mica). There is also an option to compute siderite. The basic procedure is to: 1) estimate aluminum from a combination of silicon, iron, and calcium; 2) estimate clay from the emulated aluminum, 3) estimate carbonate from calcium, and 4) estimate QFM as the remainder.

The basic premise of this standard method is that in most sedimentary rocks, total clay (kaolinite + illite + smectite + glauconite + chlorite) linearly correlates with aluminum, and it is possible to estimate aluminum from the elements silicon, calcium, and iron. 


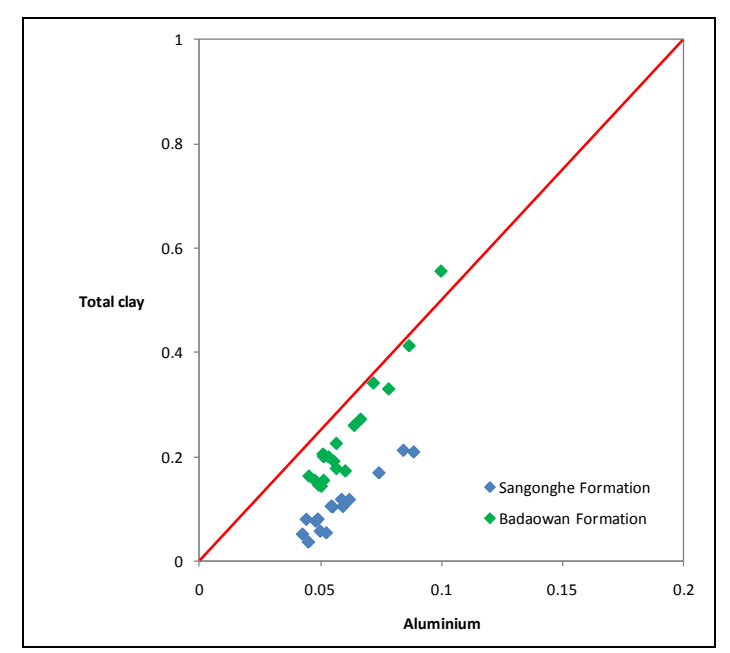

Figure 4. Relationship between aluminium and clay content.

Fig .4 shows the relationship between total clay and aluminum for these samples. The diagonal line in the clay vs. aluminum plot shows the default relationship in standard method. It can be seen that the standard model is a relatively poor representation of the relationship between aluminum and clay content for these samples, which is to be expected to have high concentrations of other aluminum-bearing minerals, such as feldspars and micas, in these samples. It is also clear from this figure that two discrete relationships between aluminum and clay content can be observed in these samples, one for the Sangonghe Formation and another one for the Badaowan Formation

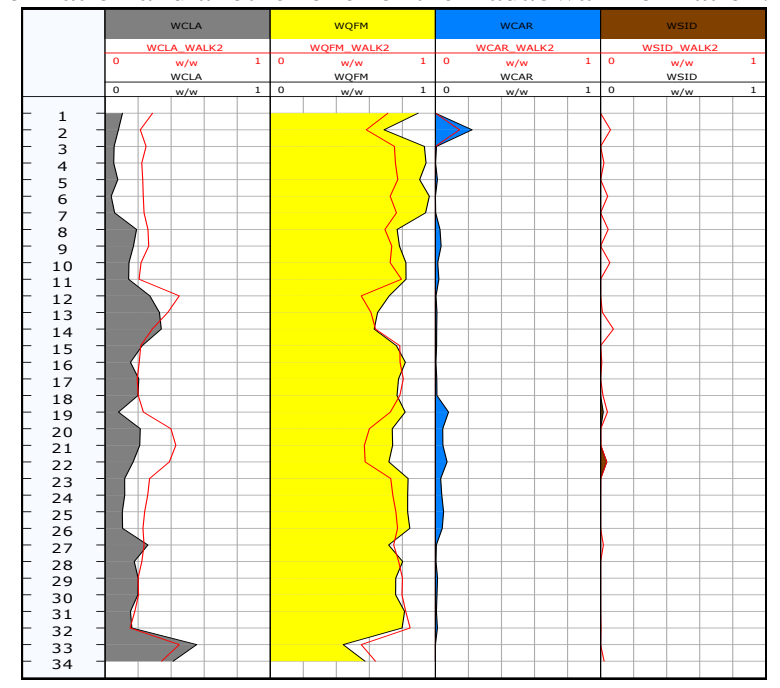

Figure 5. Comparison between measured mineralogy and mineralogy computed using the default SpectroLith* model (in red).

Fig .5 shows the comparison between measured mineralogy and mineralogy computed using the default model. Obviously, there are big differences between them and the standard error in clay estimation for the standard model is $0.091 \mathrm{w} / \mathrm{w}$. Because the very high proportions of particularly feldspars and micas make the relationship between aluminum and clay content complicated, the default model performs poorly in this situation.

To refine the estimate of clay content, new aluminum emulators and clay models were developed for the Sangonghe and Badaowan Formations separately. In addition, the carbonate model was refined based on these samples to take into account the actual composition of the carbonate minerals in these formations. With these modifications, mineralogy can be computed from the elemental concentrations using a similar scheme to the conventional model, but with replacement of the clay and carbonate models.

The relationships of clay, carbonate, and QFM contents between DR-FTIR measurements and chemical concentrations calculation using the zoned aluminumbased clay models and improved carbonate model are displayed in Fig .6 and Fig .7, which show very good match between them. The standard error in the estimation of clay content using the zoned aluminum-based clay models is $0.023 \mathrm{w} / \mathrm{w}$, there is a big improvement over using the default model.

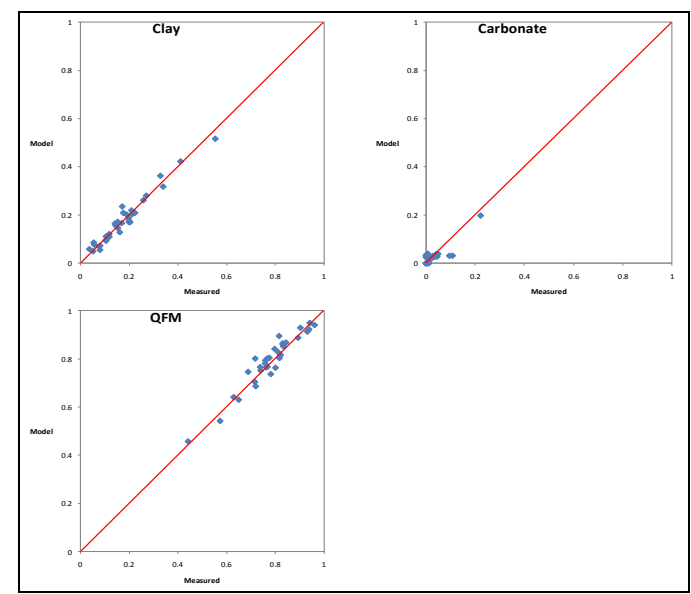

Figure 6. Relationship of clay, carbonate, and QFM contents between DR-FTIR measurements and chemical concentrations calculation using the zoned aluminium-based clay models and improved carbonate model.

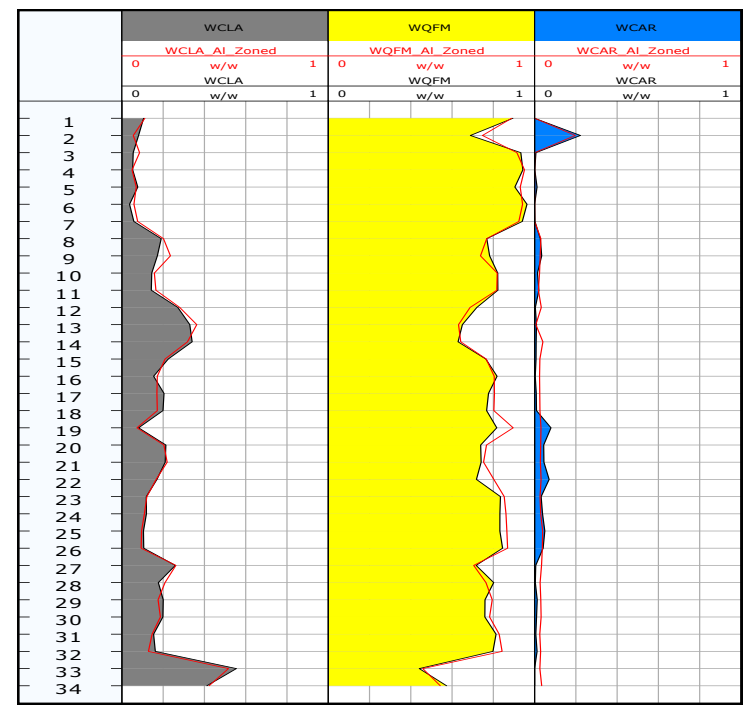

Figure 7. Comparison of measured mineralogy to mineralogy computed using the zoned aluminium-based clay models (in red)

The results of investigations conducted on the chemical and mineralogical data acquired on these samples have been applied to ECS data in the two wells for which samples are available. A comparison of core analysis and ECS results for one of the two wells included in this study is presented in Fig .8. Mineralogy results from the zoned 
aluminum-based model are compared to core mineralogy results. The two models developed have been applied separately to the Sangonghe and Badaowan Formations. In addition, key elemental concentrations from the ECS are compared to core chemical analyses.

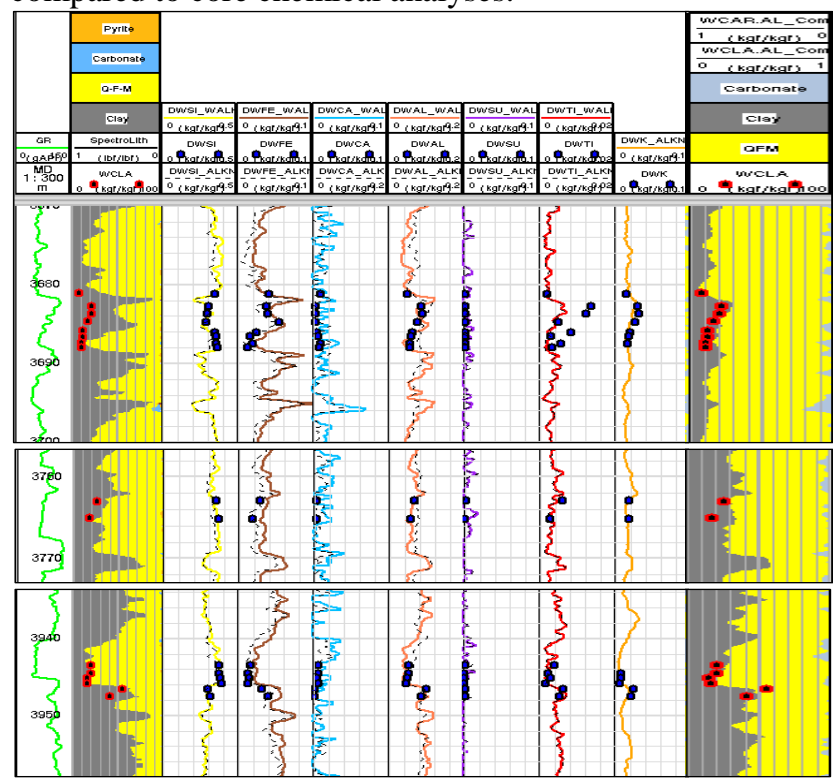

Figure 8. Core chemistry and mineralogy compared to ECS results for Well A

In general there is quite good agreement between both chemical and mineralogical results from the ECS and those obtained from core analyses. It appears that a reliable model for evaluation of chemistry and mineralogy from the ECS has been developed for application in this field.

\section{CONCLUSION}

Complex mineral composition, especially the presence of minerals such as mica, chlorite lowers the applicability of default element to mineral transformation model.

New mineral reconstruction model was built up based on the elemental and mineral measurements of core samples. Much better agreement is observed between mineralogy from cores and those determined from new mineral models of ECS logs.

\section{ACKNOWLEDGMENT}

This work was financially sponsored by the Exploration Department of Tuha Oilfield, CNPC. We would like to thank Tuha Oilfield Company, CNPC for their generosity in releasing this data, also give thanks to Tom Neville (Schlumberger) for his guidance and reviewing of the work.

\section{REFERENCES}

[1] S.J. Egbe, O.Omole, et al., "Calibration of the Elemental Capture Spectroscopy Tool Using the Niger Delta Formation”, 31st Nigeria Annual International Conference and Exhibition, Aug, 2007, doi: 10.2118/111910-MS

[2] E Eric, B.Francis, "Building a Multi-Well Model for Partitioning Spectroscopy Log Elements into Minerals Using Core Mineralogy for Calibration", SPWLA 54 ${ }^{\text {th }}$ Annual Logging Symposium, June, 2013

[3] D.M. Moore and R.C. Reynolds, "X-Ray Diffraction and the Identification and Analysis of Clay Minerals", Oxford University Press, 1989

[4] R.Z.Syed, S. Husin, "Characterization of Corrosion Products In Oil And Gas Facilities Using X-ray Powder Diffraction Method", NACE International, Mar, 2011,NACE-11393

[5] A. Matteson, and M.M. Herron, "Quantitative mineral analysis by Fourier Transform Infrared spectroscopy", Society of Core Analysts Annual Meeting, ,1993, doi:10.2118/1103023-STU

[6] M.M. Herron, A. Matteson and G. Gustavson, "Dual-range DR FTIR mineralogy and the analysis of sedimentary formations", Society of Core Analysts Conference, Aug,1997, SCA-9729

[7] S.L. Herron, and M.M. Herron, "Quantitative lithology: an application for open and cased hole spectroscopy", Transactions of the SPWLA 37th Annual Logging Symposium, Jun, 1996 SPWLA-1996-E

[8] M.M. Herron, M.E. Loan, et al., "Clay Typing, Mineralogy, Kerogen Content and Kerogen Characterization from DRIFTS Analysis of Cuttings or Core", SPE/AAPG/SEG Unconventional Resources Technology Conference,Aug,2014,doi:10.15530./urtec2014-1922653

[9] A. Matteson, and M.M. Herron, "End-Member feldspar concentrations determined by DR-FTIR spectral analysis", Journal of Sedimentary Petrology, 1993

[10] H. Susan, H. Michael, et al., "Application and Quality Control of Core Data for the Development and Validation of Elemental Spectroscopy Log Interpretation", SPWLA 55 ${ }^{\text {th }}$ Annual Logging Symposium, May,2014,SPWLA-2014-LLL 